\title{
THE ROLE OF TRYPTOPHANYL RESIDUES IN THE FUNCTION OF ASPERGILLUS NIGER GLUCOAMYLASE G1 AND G2
}

by

\author{
ANTHONY J. CLARKE and BIRTE SVENSSON
}

Department of Chemistry, Carlsberg Laboratory, Gamle Carlsberg Vej 10, DK-2500 Copenhagen Valby

Keywords: N-bromosuccinimide, acarbose, difference absorption spectroscopy, fluorescence spectroscopy

The tryptophanyl residues of the Aspergillus niger glucoamylase G1 and G2 (EC 3.2.1.3) were oxidized by $\mathrm{N}$-bromosuccinimide in both the presence and the absence of substrates and inhibitors of the enzyme. In the absence of protective ligands, 8 of 19 and 6 of 15 tryptophanyl residues in $G 1$ and $G 2$, respectively, were susceptible to modification with concomitant inactivation of the enzyme. The binding of acarbose, a potent inhibitor, prior to oxidation protected 2 tryptophanyl residues $\left(W_{a}\right.$ and $W_{b}$ ) in both $G 1$ and $G 2$ from the modification. After dissociation of acarbose-enzyme complexes with the aid of Tris, these derivatives retained about $80 \%$ of the initial enzymic activity. Further oxidation subsequently modified these 2 tryptophanyl residues resulting in total loss of activity. The substrates, maltose, maltotriose or soluble starch and the inhibitors, gluconolactone, maltitol or deoxynojirimycin protected one tryptophanyl residue $\left(W_{b}\right)$ in both $G 1$ and $G 2$ from oxidation but did not prevent the inactivation.

Characterization of the oxidized enzyme derivatives by difference UV absorption and by fluorescence spectroscopy indicated that 2 residues, $W_{a}$ and $W_{b}$, are essential in the mechanism of glucoamylase action. One residue, $W_{h}$, is apparently involved in the binding of substrate, while a second, $W_{a}$, is an integral part of a catalytically capable active center.

\footnotetext{
Abbreviations: DPCC = diphenylcarbamyl chloride; $\mathrm{G} 1$ and G2 = designate the larger and smaller forms, respectively, of glucoamylase from A. niger (29); $\mathrm{NBS}=\mathrm{N}$-bromosuccinimide; $\mathrm{nW}_{\mathrm{vx}}=$ number $(\mathrm{n})$ of oxidized tryptophanyl residues in isolated derivatives: Tris $=2$-amino-2(hydroxymethyl)-1,3-propandiol; $\mathrm{W}_{\mathrm{a}}$ and $\mathrm{W}_{\mathrm{b}}=$ ligand protected tryptophanyl residues.
} 


\section{INTRODUCTION}

Glucoamylases $(1 \rightarrow 4-\alpha$-D-glucan glucohydrolase, EC 3.2. 1.3) catalyse the release of D-glucose from the non-reducing ends of starch, glycogen and related oligosaccharides. Through kinetic studies of reactions catalysed by a glucoamylase from Rhizopus niveus, HIROMI et al. (10, 35 ) have elucidated a sub-site structure consisting of a sequence of seven affinity sites for the binding of glucose residues of linear substrates. The non-reducing terminal glucose residue initially binds at sub-site 2 and subsequently relocates to sub-site 1 to generate the productive enzyme-substrate complex $(33,35)$. While the mechanism of action of glucoamylase is not known in detail, both carboxylic acid and tryptophanyl residues appear to be essential for enzymic activity $(8,11,15,16,17,19,21,23)$. Thus, an essential tryptophanyl residue of the $R$. niveus glucoamylase is thought to be located in sub-site lof the enzyme $(19,21)$. In the glucoamylase from Aspergillus saitoi, the presence of soluble starch temporarily protected two tryptophanyl residues from NBS oxidation (16). Glucoamylase $G 1$ from $A$. niger has been inactivated by photo-oxidation of tryptophanyl residues $(3,17)$. However, the number of essential residues and their specific role in the function of the enzyme was not determined.

In the present investigation, glucoamylase from A. niger has been oxidized with NBS in both the presence and absence of various substrates and inhibitors. Different roles of two essential tryptophanyl residues are outlined and related to the structure and function of this enzyme. The susceptibility to oxidation of tryptophanyl residues of the two highly homologous forms of glucoamylase, G1 and G2, are compared and discussed in relation to the described structural differences between their polypeptide chains $(29,31)$.

\section{EXPERIMENTAL}

\subsection{Materials}

A commercial preparation of Aspergillus niger glucoamylase (AMG 200L) was obtained as a gift from Novo Industries, Bagsvaerd, Denmark. The G1 and G2 forms of the enzyme were separated and purified as previously described (29). All solutions of glucoamylase were filtered through MF-Millipore HA membranes $(0.45$ $\mu \mathrm{m})$ prior to use.

Dithiothreitol, DPCC-trypsin, maltitol, maltotriose and L-tryptophan were products of Sigma Chemical Co., St. Louis, MO. Merck, Darmstadt, F. R. G., supplied maltose monohydrate, glucono-1,5-lactone (gluconolactone), soluble starch and "System Glucose" kit, while D-glucose was purchased from BDH Chemicals, Poole, U. K.. Gluconolactone was used within 15 minutes following dissolution to minimize its hydrolysis into gluconic acid and conversion into glucono-1,4-lactone (25). N-Bromosuccinimide was a product of Fluka, Buchs, Switzerland and was re-crystallized from water prior to use. DEAE-cellulose DE52 was obtained from Whatman Ltd., Maidstone, U. K. and was pretreated according to the manufacturers instructions. Acarbose (BAY g 5421) and 1-deoxynojirimycin were generously supplied by Drs. $E$. TRusCheIt and D. SCHMIDT, Bayer AG, Wuppertal, F. R. G.

\subsection{Analytical procedures}

Concentrations of glucoamylase were determined spectrophotometrically employing the $\varepsilon_{280}$ values of $1.37 \times 10^{5}$ and $1.09 \times 10^{5} \mathrm{M}^{-1} \times \mathrm{cm}^{-1}$ for G1 and G2, respectively. Amino acid analyses were performed using a Durrum D-500 amino acid analyzer. The protein samples (15-17 $\mu \mathrm{g})$ were hydrolysed with $200 \mu \mathrm{l}$ of $6 \mathrm{M}-\mathrm{HCl}$ in sealed, evacuated tubes at $110^{\circ} \mathrm{C}$ for 24 hours. Glucoamylase activity was determined with maltose $(15 \mathrm{~mm})$ as substrate and the liberated glucose was measured as previously described (29). CD spectra were measured with a CNRS Roussel-Jouan Dichrograph Model 3 spectropolarimeter at room temperature in $0.2 \mathrm{~cm}$ pathlength cells. The enzyme concentrations employed were approximately $0.9 \mu \mathrm{M}$ and approximately $10 \mu \mathrm{M}$ for the wavelength regions $200-250 \mathrm{~nm}$ and $240-320 \mathrm{~nm}$, respectively.

\subsection{Chemical modification with NBS}

The procedure employed for the modification of glucoamylase with NBS was essentially that of 
PATCHORNIK et al. (22) and SPANDE and WITKOP (28). The modification was performed on both an analytical and a preparative scale.

\subsubsection{Analytical scale modification}

Glucoamylase $(12-17 \mu \mathrm{M}, 1.0 \mathrm{ml})$ in $50 \mathrm{~mm}$ sodium acetate $\mathrm{pH} 4$. 3, and NBS ( $10 \mathrm{mM}, 5-50$ $\mu \mathrm{l})$ were mixed in a $10 \mathrm{~mm}$ pathlength cuvette, thermostated at $25^{\circ} \mathrm{C}$. Following two minutes of incubation, the absorbance at $280 \mathrm{~nm}$ was recorded and corrected for dilution. The number of modified tryptophanyl residues were calculated as described by SPANDE and WITKOP (28) using a $-\Delta \varepsilon_{280}$ value of 4,200 and molar absorbtivities of $1.37 \times 10^{5} \mathrm{M}^{-1} \times \mathrm{cm}^{-1}$ and $1.09 \times 10^{5} \mathrm{M}^{-1} \times \mathrm{cm}^{-1}$ for $\mathrm{G} 1$ and $\mathrm{G} 2$, respectively. The chemical modification of the enzymes with NBS was also monitored by the change in fluorescence intensity at $340 \mathrm{~nm}$. Finally, an aliquot $(50 \mu \mathrm{l})$ of $15 \mathrm{~mm}$-L-tryptophan was added to destroy any residual NBS and the mixture was dialysed initially against water and then against $50 \mathrm{~mm}$-sodium acetate $\mathrm{pH} 4.3$. Enzyme samples treated in a similar manner except for the addition of NBS served as controls. The remaining specific activities of the modified enzyme preparations were determined and expressed as a percentage of the control.

In a series of parallel experiments both $\mathrm{Gl}$ and G2 solutions were treated with NBS in the presence of either: maltose ( $24 \mathrm{mM})$, maltotriose (25 mM), maltitol (18 mM), glucose (100 mM), gluconolactone (24 mM), deoxynojirimycin (1.5 $\mathrm{mM})$, acarbose $(0.15 \mathrm{mM})$ or soluble starch $(1 \%$ $\mathrm{wt} / \mathrm{vol})$. In the case of acarbose protection, modified dialysis procedures were required to remove the tightly bound inhibitor from the enzyme. Thus, following the NBS oxidation and quenching with tryptophan, the reaction mixture was first dialysed against water to remove excess of reagents and subsequently against 10 volumes of $1.6 \mathrm{M}$-Tris- $\mathrm{HCl}, \mathrm{pH} 7.6\left(4{ }^{\circ} \mathrm{C}, 3\right.$ changes over 20 hours) to dissociate the enzymeacarbose complex and eliminate acarbose. The Tris- $\mathrm{HCl}$ was removed by dialysis against water and the enzyme was finally re-equilibrated in 50 mM-sodium acetate $\mathrm{pH} 4.3$ by dialysis. In experiments employing starch as the protective ligand, the residual starch and hydrolysis products were separated from the enzyme preparations by ion-exchange chromatography. The reaction mixtures were applied to columns of DEAE-cellulose $(0.5 \times 4 \mathrm{~cm})$ equilibrated and eluted with $50 \mathrm{~mm}$-sodium phosphate, $\mathrm{pH}$ 7.0. Fractions were monitored for both total carbohydrate by the phenol-sulfuric acid procedure of DuBoIs et al. (6) and absorbance at $280 \mathrm{~nm}$. The enzyme derivatives were eluted with the equilibration buffer containing $0.3 \mathrm{M}-\mathrm{NaCl}$. The specific activity was expressed as a percentage of a control which was subjected to all of the above conditions except for the addition of NBS.

\subsubsection{Preparative scale modifications}

Aliquots (30-200 $\mu \mathrm{l})$ of $10 \mathrm{~mm}$-NBS were sequentially added to solutions (20-40 ml) of G1 or $\mathrm{G} 2(17 \mu \mathrm{M})$ in $50 \mathrm{mM}$-sodium acetate, $\mathrm{pH} 4.3$. When no further decrease in $\mathrm{A}_{280}$ was observed, tryptophan (400-1000 $\mu \mathrm{l}, 15 \mathrm{~mm}$ ) was immediately added to quench the residual oxidant. The excess reagents were removed by dialysis as outlined above (section 2.3.1). To minimize precipitation of the enzymatically inactive derivatives, prolonged standing of the solutions was avoided.

\subsection{Difference absorption spectra}

The difference absorption spectra of glucoamylase preparations produced by either substrates or inhibitors, were obtained with either a Cary Model 219 or a Varian Model 2200 recording spectrophotometer at $25^{\circ} \mathrm{C}$. Samples ( $1.0 \mathrm{ml}$ in $10 \mathrm{~mm}$ pathlength double chamber cuvettes) of the enzyme solution ( $9-13 \mu \mathrm{M}$ in 50 mM-sodium acetate, $\mathrm{pH} 5.0$ ) were placed into both the reference and sample compartments of the spectrophotometer. A $50 \mu \mathrm{l}$ aliquot of an appropriate stock solution of the ligand was added to the enzyme solution in the sample cuvette to achieve the desired molar excess over the protein. An equal volume was added of: 1) ligand to the buffer solution in the first chamber of the reference cuvette, 2) buffer to the enzyme solution in its second chamber. Spectra were recorded at $0.2 \mathrm{~nm} \times \mathrm{sec}^{-1}$ using a full scale of either 0.02 or 0.05 absorbance units. In the case 
of gluconolactone the spectra were recorded within 20 seconds after mixing the enzyme with the inhibitor to maintain a saturating concentration of the intact ligand throughout the course of the recording.

\subsection{Fluorescence spectra and titration}

The fluorescence spectra of the enzymes were measured with a Jasco Model FP550 spectrofluorometer. All measurements were performed in $50 \mathrm{~mm}$-sodium acetate, $\mathrm{pH} 4.3$ and at $25^{\circ} \mathrm{C}$.

The excitation spectra of either $\mathrm{G} 1$ or $\mathrm{G} 2$ show maximum at $280 \mathrm{~nm}$, while the emission is strongest at $340 \mathrm{~nm}$. Hence, the fluorescence intensity changes caused by either the NBS oxidation of glucoamylase or the binding of ligands to the native enzyme and its various derivatives were observed at $340 \mathrm{~nm}$ with excitation at $280 \mathrm{~nm}$. The fluorescence titration was performed as follows: an appropriate volume of a concentrated ligand solution $(2.5-10 \mu l)$ was added to the enzyme solution (1.8-2.0 $\mu \mathrm{M}, 3.0$ $\mathrm{ml}$ ) in the quartz cell. The fluorescence intensity was measured after each addition, corrected for dilution and expressed as the percentage of the fluorescence intensity difference $(\Delta \mathrm{F} \%)$ relative to the fluorescence intensity of the free enzyme, i. e.:

$$
\Delta \mathrm{F} \%=\frac{\mathrm{F}_{\mathrm{i}}-\mathrm{F}_{\mathrm{f}}}{\mathrm{F}_{\mathrm{i}}} \times 100 \%
$$

where $F_{i}$ and $F_{r}$ are the initial and final fluorescence intensities, respectively. The apparent dissociation constant of the enzyme-ligand complex, $\mathbf{K}_{\mathrm{d}}$, and the maximum value of the percentage change of relative fluorescence intensity, $\Delta \mathrm{F} \%_{\max }$, obtainable under ligand saturating conditions are given by the following equation ( 12 , 34):

$$
\Delta \mathrm{F} \%=\frac{\Delta \mathrm{F} \%_{\max }[\mathrm{I}]}{\mathrm{K}_{\mathrm{d}}+[\mathrm{I}]}
$$

where [I] is the concentration of inhibitor. Values of $K_{d}$ and $\Delta F \%_{\max }$ of the enzyme derivatives for the various inhibitors were estimated from double reciprocal plots of the change in fluorescence intensity versus inhibitor concentration.

\subsection{Tryptic digestion}

Samples $(2.5 \mathrm{mg})$ of glucoamylase derivatives were dissolved in $2.0 \mathrm{ml}$ of $100 \mathrm{mM}-\mathrm{NaCl}$ and the $\mathrm{pH}$ was adjusted to 8.0 with $50 \mathrm{~mm}-\mathrm{NaOH}$. To these solutions was added $100 \mu l$ of DPCCtrypsin $\left(4.1 \mathrm{mg} \times \mathrm{ml}^{-1}\right.$ in $100 \mathrm{~mm}-\mathrm{NaCl}$ ). The digestions were performed at $37{ }^{\circ} \mathrm{C}$ with constant stirring under a nitrogen atmosphere. The reactions were followed by monitoring the uptake of $10 \mathrm{~mm}-\mathrm{NaOH}$ with time in a pH-Stat. The results were corrected for the uptake of alkali by a solution containing only trypsin and incubated under similar conditions. For comparison purposes, a sample of glucoamylase was reduced and alkylated with 2-vinylpyridine, as previously described $(30,31)$, and subjected to tryptic digestion.

\section{RESULTS}

\subsection{Oxidation of $\mathbf{G} \mathbf{1}$ and $\mathbf{G} 2$}

Oxidation of the two forms of A. niger glucoamylase with NBS resulted in a loss of absorbance at $280 \mathrm{~nm}$ and a concomitant increase in absorbance at $250 \mathrm{~nm}$. The difference absorption spectra were characterized by a minimum at 282 $\mathrm{nm}$, with a shoulder at $290 \mathrm{~nm}$, a maximum at $310 \mathrm{~nm}$ and two isobestic points at $300 \mathrm{~nm}$ and $264 \mathrm{~nm}$, respectively (Figure 1). Reaction of G1 with NBS modified approximately 8 of 19 tryptophanyl residues ( $\mathrm{G} 1-8 \mathrm{~W}_{\mathrm{ox}}$ ), while in $\mathrm{G} 2$ under the same conditions approximately 6 of 15 $\left(G 2-6 W_{o x}\right)$ were modified (Figure 2).

The modification of both G1 and G2 with NBS was also followed by the changes in fluorescence intensity at $340 \mathrm{~nm}$ (Figure 3 ). At an NBS to enzyme molar ratio of 25 , where 6 residues of $\mathrm{G} 2$ are modified (see Figure 2), $87 \%$ of the initial intrinsic fluorescence is lost. Thus, these 6 tryptophanyl residues express nearly all of the intrinsic fluorescence of $\mathrm{G} 2$ and must be readily accessible to solvent. Similarly, $85 \%$ of the initial intrinsic fluorescence of $\mathrm{Gl}$ is lost in G1-8W $W_{\text {ox }}$ at an NBS to enzyme molar ratio of 25 .

A decrease in activity accompanied the oxidation of both $\mathrm{Gl}$ and $\mathrm{G} 2$ such that the fully modified preparations, G1-8 $\mathrm{W}_{\mathrm{ox}}$ and $\mathrm{G} 2-6 \mathrm{~W}_{\mathrm{ox}}$ were inactive (Figures $4 \mathrm{~A}$ and $\mathrm{B}$, respectively). The appearance of turbidity was noted in these samples upon standing or after dialysis. 


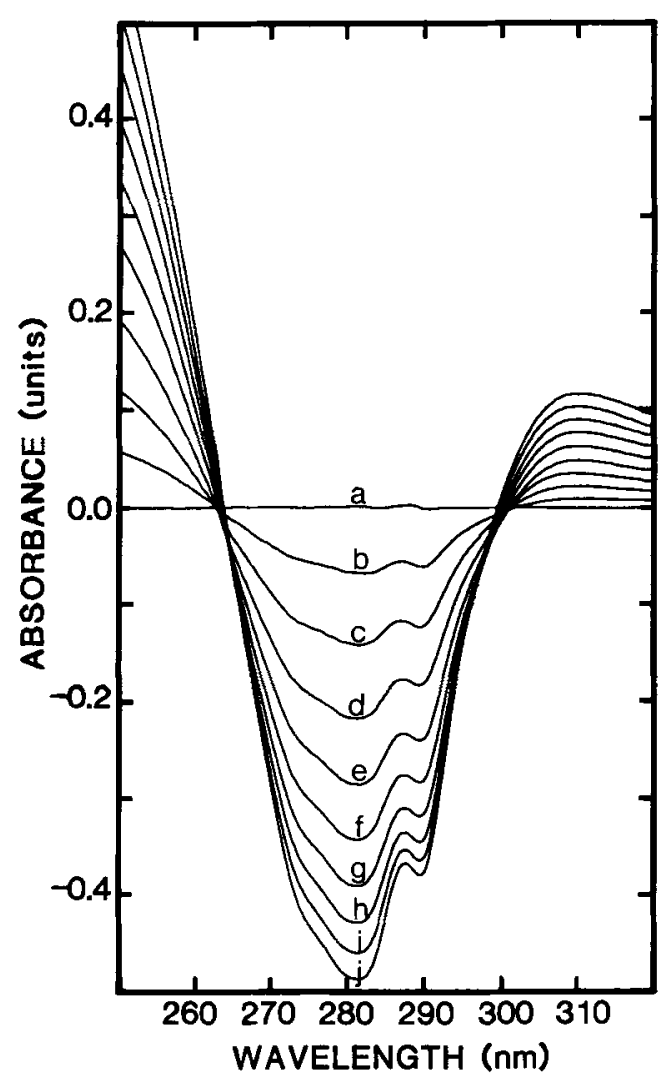

Figure 1. Difference absorption spectra of Gl induced by NBS oxidation. Enzyme, $12.8 \mu \mathrm{M}$; NBS: a, $0 \mu \mathrm{M}$; b, $35.1 \mu \mathrm{M} ; \mathrm{c}, 70.2 \mu \mathrm{M}$; d, $105 \mu \mathrm{M} ; \mathrm{e}, 140 \mu \mathrm{M} ; \mathrm{f}, 176$ $\mu \mathrm{M} ; \mathrm{g}, 211 \mu \mathrm{M} ; \mathrm{h}, 246 \mu \mathrm{M} ; \mathrm{i}, 281 \mu \mathrm{M} ; \mathrm{j}, 316 \mu \mathrm{M}$.

\subsection{Amino acid analysis}

The possibility that the loss in enzymic activity was caused by the oxidation of amino acid residues other than tryptophan was investigated by amino acid analysis. SPANDE and WITKOP (28) have indicated that the rate of NBS oxidation of amino acid residues follows the order: Trp $>$ Tyr $>$ Met/His. The partial amino acid composition of glucoamylase preparations oxidized to varying extents are listed in Table I. In both G1 and G2, the Met and His contents remained constant throughout the reaction. Partially oxidized $\mathrm{G} 1$, retaining $21 \%$ activity, still possessed the same number of tyrosyl residues as the native enzyme, while fully modified G1 lost 3 tyrosyl residues. However, in Gl oxidized in

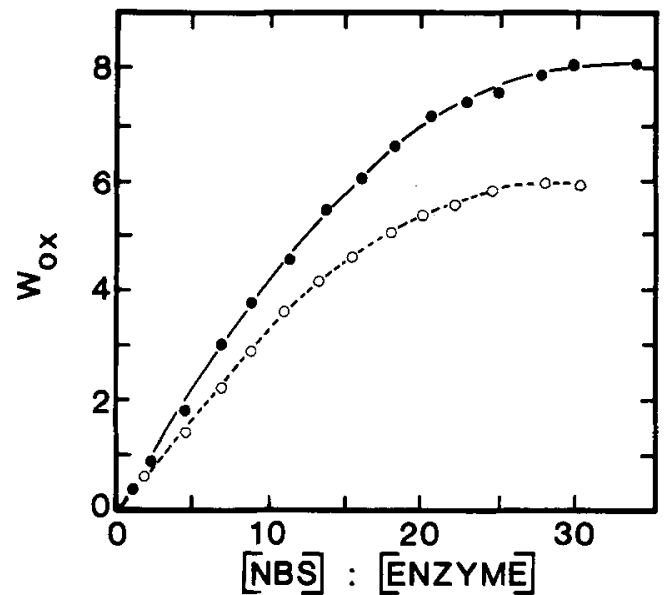

Figure 2. The NBS oxidation of glucoamylase G1 (- - and G2 (--.--) Samples $(1.0 \mathrm{ml})$ of $\mathrm{G} 1(13 \mu \mathrm{M})$ and $\mathrm{G} 2(12 \mu \mathrm{M})$ in $50 \mathrm{~mm}$-sodium acetate,

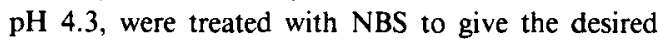
molar excess of the reagent over protein.

the presence of acarbose and retaining $82 \%$ of its original activity (see section 3.3) 4 tyrosyl residues were modified. This indicated that tyrosyl residues are not essential for the enzymic activity. Similar results were obtained in parallel experiments employing $\mathrm{G} 2$.

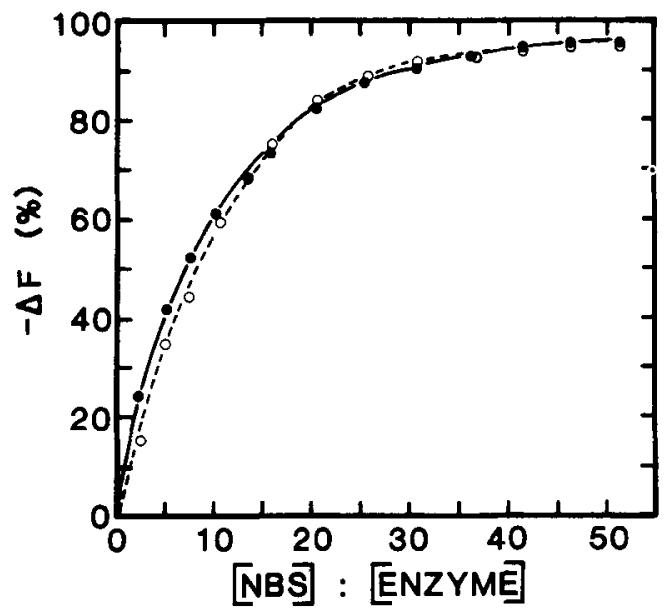

Figure 3. Relative fluorescence intensity changes $(\triangle \mathrm{F} \%)$ of $\mathrm{Gl}\left(\longrightarrow-{ }_{-}\right)$and $\mathrm{G} 2\left(--\mathrm{O}_{----)}\right.$with NBS oxidation. Samples $(3.0 \mathrm{ml})$ of $\mathrm{Gl}(6.5 \mu \mathrm{M})$ and $\mathrm{G} 2(6.7 \mu \mathrm{M})$ in $50 \mathrm{~mm}$-sodium acetate, $\mathrm{pH} 4.3$, were treated with NBS to give the desired molar excess of the reagent over protein. 


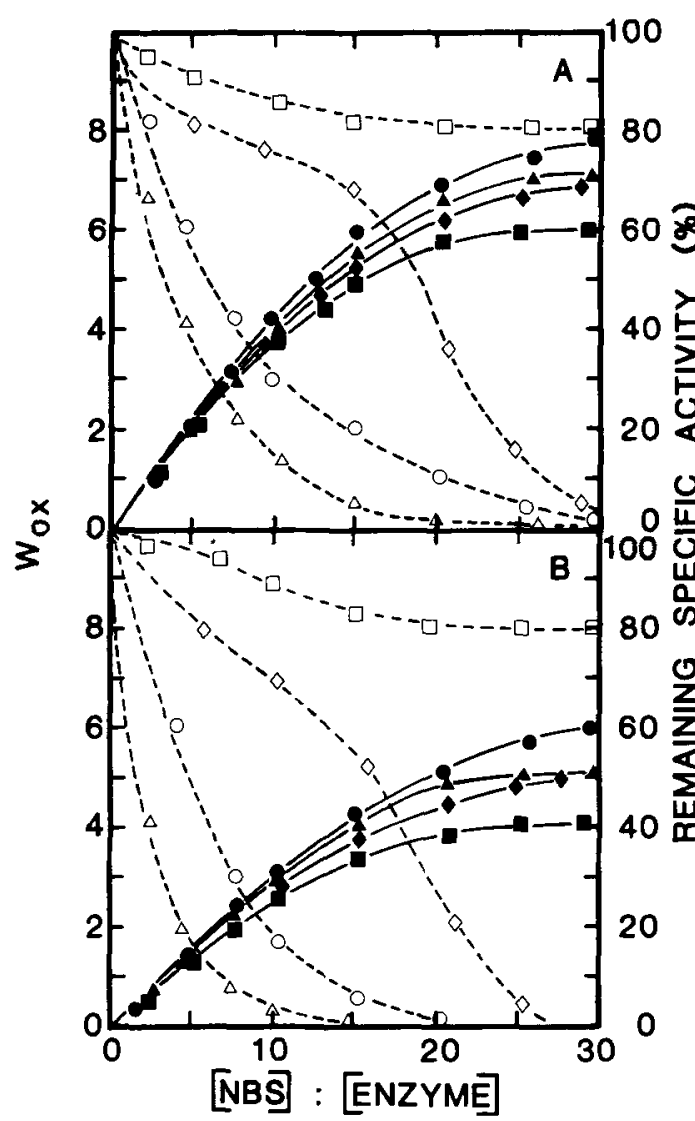

\subsection{Oxidation of $\mathrm{G} 1$ and $\mathrm{G} 2$ in the presence of ligands}

The involvement of specific tryptophanyl residues in the glucoamylase catalysis was investigated by NBS oxidation of both G1 and G2 protected by either the substrates, maltose, maltotriose, and soluble starch, or the inhibitors, acarbose, maltitol, gluconolactone, glucose, and
Figure 4. NBS oxidation of G1 (A) and G2 (B) in the absence and presence of substrates and inhibitors. Enzyme $(12 \mu \mathrm{M})$ in $1.0 \mathrm{ml}$ of $50 \mathrm{~mm}$-sodium acetate, $\mathrm{pH} 4.3$, was oxidized with various concentrations of NBS in both the absence and presence of $100 \mathrm{~mm}$-glucose (-); in the presence of: $24 \mathrm{~mm}$-maitose $25 \mathrm{~mm}$ maltotriose, $18 \mathrm{~mm}$-maltitol, $24 \mathrm{~mm}$-gluconolactone or $1.5 \mathrm{~mm}$-deoxynojirimycin $(\mathbf{\Lambda}) ; 0.15 \mathrm{~mm}$-acarbose $(\square) ; 1 \%(\mathbf{w t} / \mathrm{vol})$ soluble starch (\$).

Remaining specific activity (\%) of samples prepared in both the absence and presence of glucose, maltitol, gluconolactone or deoxynojirimycin $(O)$; in the presence of acarbose $(\square)$; soluble starch $(\diamond)$; maltose or maltotriose $(\Delta)$.

deoxynojirimycin (Figure $4 \mathrm{~A}$ and $\mathrm{B}$ ). In the presence of the pseudotetrasaccharide acarbose, a potent inhibitor of glucoamylases (37), only 6 tryptophanyl residues of $\mathrm{G} 1$ could be modified yielding $\mathrm{G} 1-6 \mathrm{~W}_{\mathrm{ox}}$. Acarbose thus protected two tryptophanyl residues (in the following designated $W_{a}$ and $W_{b}$ ) against oxidation. After removal of the acarbose by the procedure outlined in section 2.3 .1 , approximately $80 \%$ of the specific activity was regained. In contrast maltose, maltotriose, soluble starch, gluconolactone or deoxynojirimycin protected only a single tryptophanyl residue, which we assume to be $W_{b}$, from NBS oxidation (Figure 4A). Moreover, after removal of the ligand, the corresponding G1-7 $\mathrm{W}_{\text {ox }}$ derivative was enzymically inactive and turbidity was observed upon prolonged standing as with G1-8W strate or inhibitor from each of the above G1$6 \mathrm{~W}_{\mathrm{ox}}$ and $\mathrm{G} 1-7 \mathrm{~W}_{\mathrm{ox}}$ preparations by dialysis and repeated oxidation with NBS resulted in the modification of the previously protected tryptophanyl residue(s), to yield inactive $\mathrm{Gl}-8 \mathrm{~W}_{\mathrm{ox}}$.

Table I.

Partial amino acid composition of both native and oxidized preparations of G1.

\begin{tabular}{lccccc}
\hline $\begin{array}{l}\text { Enzyme } \\
\text { derivative }\end{array}$ & $\begin{array}{c}\text { Residual } \\
\text { activity }\end{array}$ & $(\%)$ & \multicolumn{2}{c}{$\begin{array}{c}\text { Amino acid } \\
\text { (residues } \times \text { mole }\end{array}$} \\
\cline { 3 - 6 } of enzyme)
\end{tabular}


Figure 5. Difference absorption spectra of glucoamylase induced by gluconolactone. Inhibitor, $21 \mathrm{~mm}$; enzyme $(11 \mu \mathrm{M})$ in $50 \mathrm{~mm}$-sodium acetate, pH 5.0:

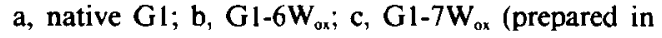
the presence of maltose); $\mathrm{d}, \mathrm{G} 1-8 \mathrm{~W}_{\mathrm{ox}}$; e, baseline.

Similar results were obtained in parallel experiments involving G2 (Figure 4B). Acarbose protected two tryptophanyl residues $\left(\mathrm{W}_{\mathrm{a}}\right.$ and $W_{b}$ ) from modification with retention of about $80 \%$ of the specific activity. The other ligands protected only one tryptophanyl residue, again assumed to be $W_{b}$, from NBS oxidation and the resulting $\mathrm{G} 2-5 \mathrm{~W}_{\text {ox }}$ preparations, were devoid of catalytic activity. Dissociation of the complexes followed by treatment with NBS resulted in oxidation of all of the 6 susceptible tryptophanyl residues yielding inactive $\mathrm{G} 2-6 \mathrm{~W}_{\mathrm{ox}}$.

Glucose, a competitive inhibitor considered to bind sub-site 2 of glucoamylases $(9,12)$, did not afford any protection against neither NBS oxidation of tryptophanyl residues nor loss of enzymic activity in both $\mathrm{G} 1$ and G2.

\subsection{Difference spectroscopy}

A difference spectrum of native $G 1$ was induced by the inhibitor gluconolactone as shown in Figure 5a. The spectrum was characterized by peaks at $292 \mathrm{~nm}$ and $301-303 \mathrm{~nm}$ and troughs at both 282 and $289 \mathrm{~nm}$. The binding of acarbose was found to produce specific spectral changes with troughs at $272 \mathrm{~nm}, 282 \mathrm{~nm}$, and $290 \mathrm{~nm}$ and a peak at $294 \mathrm{~nm}$ with a shoulder at 300-305 $\mathrm{nm}$ (Figure 6a). Similar spectra to those induced in G1 were observed with native G2 (results not shown). The difference absorption spectra of oxidized G1 preparations induced by either gluconolactone or acarbose are also illustrated in Figures 5 and 6, respectively. The difference spectra of both G1-6W and G1-7W ox are very similar to those of the native enzymes with respect to shape, while the intensity of peaks and troughs decreased (Figures $5 b$ and $c, 6 b$ and c). In contrast, acarbose or gluconolactone induced only minor spectral changes in the fully oxidized G1-8 $W_{o x}$ (Figures $6 d$ and 5d, respectively).

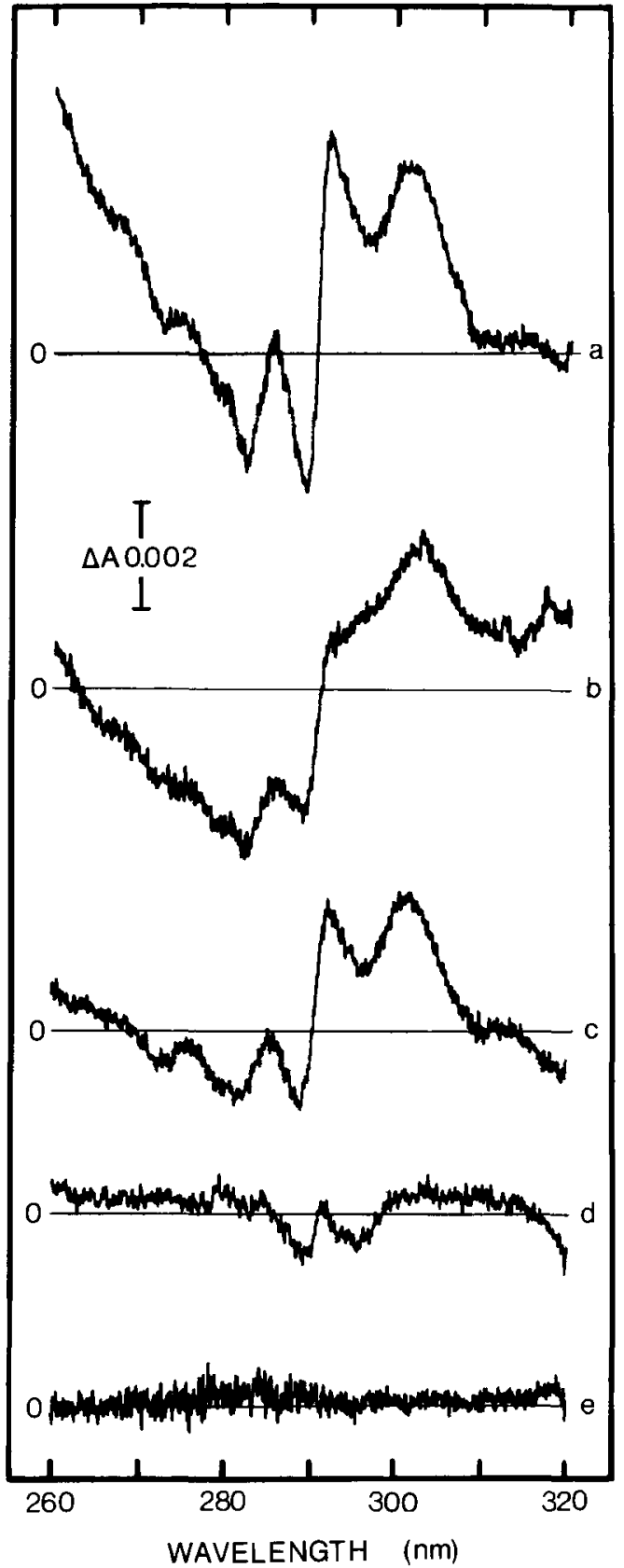

\subsection{Fluorescence titrations}

The fluorescence spectra of native $G 1$ in the absence and presence of maltose, gluconolactone and acarbose are shown in Figure 7. The intrinsic fluorescence intensity of the glucoamylase decreased with the addition of either maltose or gluconolactone and a slight blue shift of 
$4 \mathrm{~nm}$ in the fluorescence maximum was observed. The binding of acarbose, on the other hand, induced an increase in the fluorescence intensity

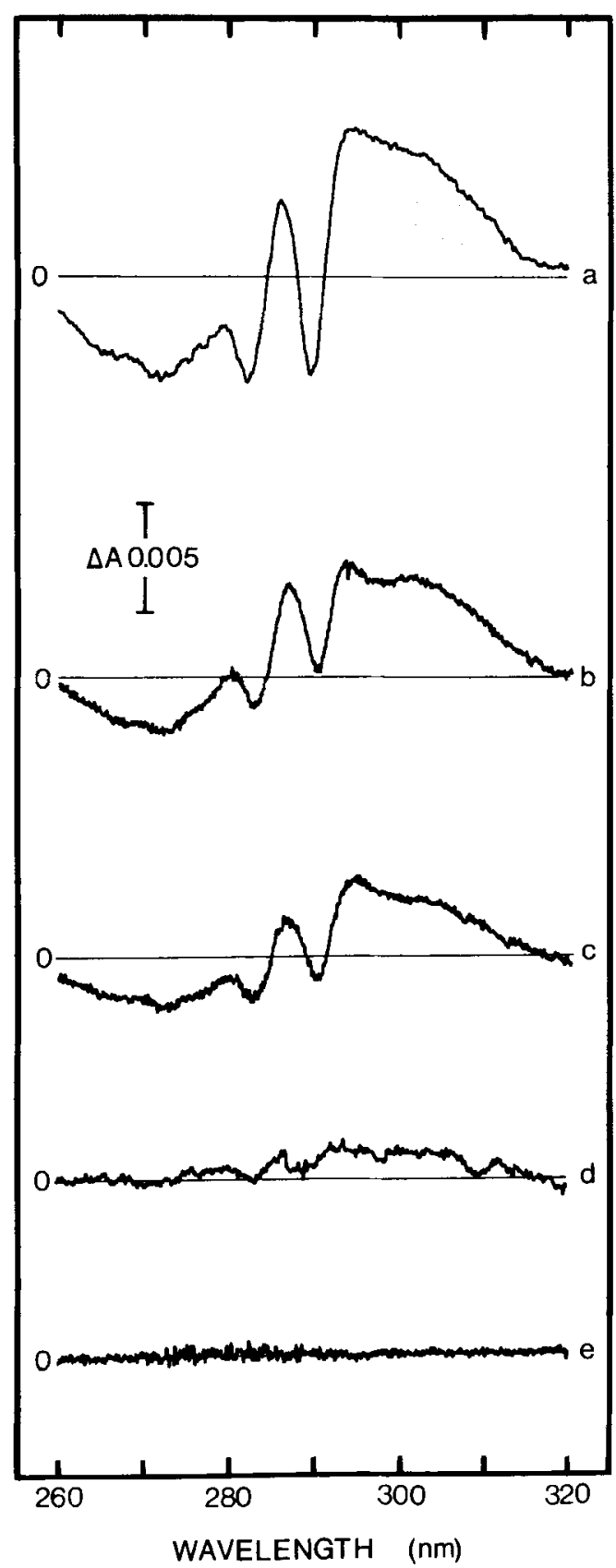

Figure 6. Difference absorption spectra of glucoamylase induced by acarbose. Inhibitor, $0.15 \mathrm{~mm}$; enzyme $(11 \mu \mathrm{M})$ in $50 \mathrm{~mm}$-sodium acetate, pH 5.0: a, native $\mathrm{G} 1 ; \mathrm{b}, \mathrm{G} 1-6 \mathrm{~W}_{\mathrm{ox}} ; \mathrm{c}, \mathrm{Gl}-7 \mathrm{~W}_{\text {ox }}$ (prepared in the presence of maltose); d, G1-8 $W_{o x}$; e, baseline. and a $5 \mathrm{~nm}$ red shift in the fluorescence maximum. A fluorometric titration of both the native glucoamylase and oxidized derivatives with both gluconolactone and acarbose was performed to yield values for the maximum fluorescence intensity changes $\left(\Delta F_{\max }\right)$ and the apparent dissociation constants $\left(\mathrm{K}_{\mathrm{d}}\right)$. The results are summarized in Table II.

\subsection{Conformational studies}

The CD spectra (not shown) of either the fully oxidized G1-8 $W_{o x}$ or $G 2-6 W_{o x}$ were characterized by gross changes in the region between 250-300 $\mathrm{nm}$ due to destruction of tryptophan. However, very little change was observed in the region between the wavelengths $200-240 \mathrm{~nm}$, which is attributed to the peptide backbone of proteins.

Further structural information on the oxidized derivatives of glucoamylase was obtained

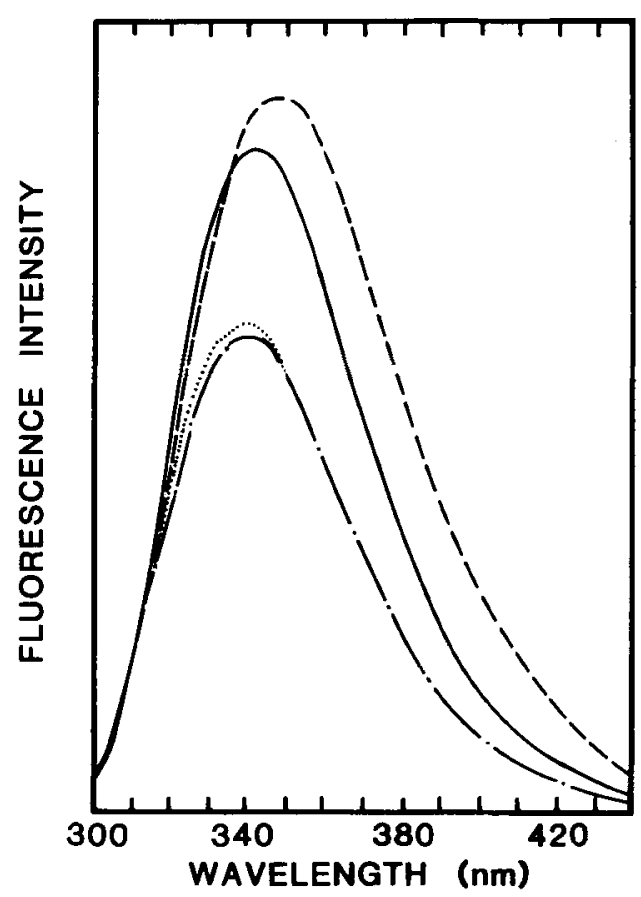

Figure 7. Fluorescence emission spectra of glucoamylase in the absence and presence of ligands. Enzyme, $\mathrm{G} 1(5.4 \mu \mathrm{M})$ in $50 \mathrm{~mm}$-sodium acetate, $\mathrm{pH} 5.0$ at 25 ${ }^{\circ} \mathrm{C}$ in the absence (-) and presence of: $14 \mathrm{~mm}-$ maltose (_- - - - $), 12 \mathrm{~mm}$-gluconolactone (--.-.) or $0.15 \mathrm{~mm}$-acarbose (-- - - ). 
Table II.

Apparent dissociation constants, $K_{\downarrow}$, of glucoamylase derivatives and maximum fluorescence change, $\Delta \mathbf{F}_{\max }$, induced by inhibitors.

\begin{tabular}{|c|c|c|c|c|}
\hline \multirow{2}{*}{$\begin{array}{l}\text { Enzyme } \\
\text { preparation }\end{array}$} & \multicolumn{2}{|c|}{ Acarbose } & \multicolumn{2}{|c|}{ Gluconolactone } \\
\hline & $\begin{array}{c}\Delta \mathrm{F}_{\max } \\
(\%)\end{array}$ & $\begin{array}{c}K_{d} \\
(\mu \mathrm{M})\end{array}$ & $\begin{array}{l}\Delta F_{\max } \\
(\%)\end{array}$ & $\underset{(\mathrm{mM})}{\mathrm{K}_{\mathrm{d}}}$ \\
\hline Native Gl & +15 & 1.0 & -20 & 1.0 \\
\hline G1-6W & +35 & 1.0 & -36 & 0.75 \\
\hline G1-7W $W_{o x}$ & +33 & 1.7 & -32 & 1.1 \\
\hline G1-8W $W_{o x}$ & 0 & - & 0 & - \\
\hline Native G2 & +21 & 0.72 & -27 & 1.0 \\
\hline G2-4W & +24 & 1.5 & -37 & 0.69 \\
\hline$G 2-5 W_{o x}$ & +24 & 1.8 & -35 & 1.0 \\
\hline G2-6W & 0 & - & 0 & - \\
\hline
\end{tabular}

through enzymatic digestion with trypsin. The time course of the proteolysis of both native and three oxidized forms of $\mathrm{G} 2$ is illustrated in Figure 8. Native G2 was relatively resistant to proteolysis while oxidized and enzymatically active $\mathrm{G} 2\left(\mathrm{G} 2-4 \mathrm{~W}_{\mathrm{ox}}\right)$ was digested to an extent of about $30 \%$ of that of completely unfolded G2 prepared by reduction and alkylation. Oxidized and enzymatically inactive derivatives of $\mathrm{G} 2\left(\mathrm{G} 2-5 \mathrm{~W}_{\mathrm{ox}}\right.$ and $\left.\mathrm{G} 2-6 \mathrm{~W}_{\mathrm{ox}}\right)$ were more susceptible, as the extent of digestion in both cases attained about $70 \%$ of that of unfolded $\mathrm{G} 2$ (Figures $8 \mathrm{c}$ and $\mathrm{d}$ ).

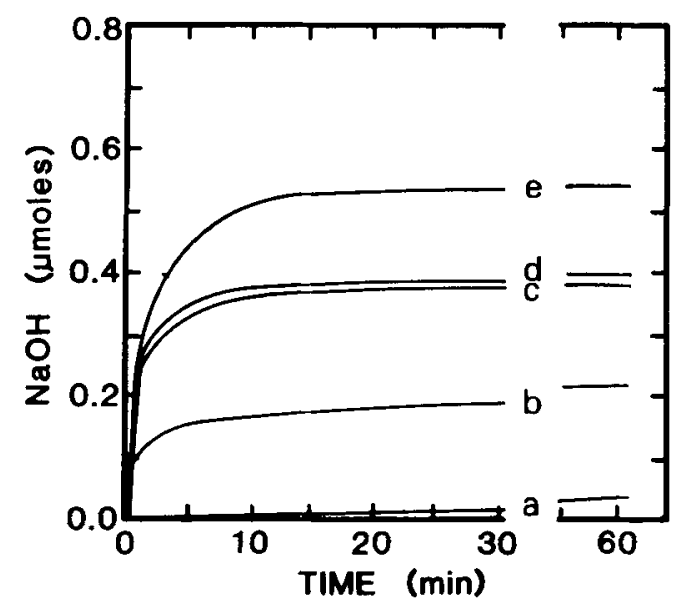

Figure 8. Tryptic digestion of native $G 2$ (a), G2-4W (b), G2-5W ox (c), G2-6Wox (d) and 2-pyridylethylated G2 (e). The reactions were followed by the uptake of $10 \mathrm{~mm}-\mathrm{NaOH}$ with time at $\mathrm{pH} 8.0$ and $37^{\circ} \mathrm{C}$.

\section{DISCUSSION}

$\mathrm{N}$-Bromosuccinimide was found to modify 8 of 19 and 6 of 15 tryptophanyl residues of the two forms of the glucoamylase from A. niger, $G 1$ and $G 2$, respectively. This modification imparts complete loss of enzymic activity, indicating that one or more of the susceptible tryptophanyl residues constitute(s) a portion of the active center. In the presence of specific ligands, the NBS oxidation of glucoamylase suggested the existence of two essential tryptophanyl residues, designated $W_{a}$ and $W_{b}$, each with distinct functional properties.

The protection of one tryptophanyl residue, $W_{b}$, in both $G 1$ and $G 2$ by all of the employed substrates and inhibitors, except glucose, suggests a role of this residue in the binding of ligands. The dissociation constants for the partially oxidized enzyme and these ligands were found to be essentially the same as with the unmodified enzyme. Furthermore, the destruction of this binding site is implicated by the abolition of the UV difference absorbance signal of the completely oxidized preparations, G1$8 \mathrm{~W}_{\mathrm{ox}}$ and $\mathrm{G} 2-6 \mathrm{~W}_{\mathrm{ox}}$. Since the protective inhibitors of this study bind to sub-site 1 of other glucoamylases $(10,12,20,34,35)$, the protected tryptophanyl residue is suggested to be located in sub-site 1 of the $A$. niger glucoamylase. Accordingly, glucose which binds at sub-site 2 $(9,12)$, did not prevent the oxidation of tryptophanyl residues in neither G1 nor G2. The finding that the derivatives, G1-7 $W_{\mathrm{ox}}$ and G2- 
$5 \mathrm{~W}_{\text {ox }}$, with an intact tryptophanyl residue presumably in sub-site 1 , were totally devoid of catalytic activity implied the requirement of a second tryptophanyl residue for catalysis to occur. Indeed, the binding of acarbose to the enzyme before oxidation provided the protection of two tryptophans, $W_{a}$ and $W_{b}$, and such derivatives (G1-6 $W_{o x}$ and $\left.G 2-4 W_{o x}\right)$ maintained about $80 \%$ of the original specific activity.

The role of this second tryptophanyl residue, $W_{a}$, in the mechanism of enzymic action is unclear. However, its oxidation seemed not to hinder ligand binding as shown with the inactive derivatives, G1-7 $W_{\mathrm{ox}}$ and $\mathrm{G} 2-5 \mathrm{~W}_{\mathrm{ox}}$. As it was oxidized in the presence of substrate and therefore probably not required for substrate binding, it is conceivable that $W_{a}$ is essential in maintaining the structural integrity of the active enzyme. The increase in polarity accompanying the oxidation of the tryptophan to oxindolealanine is likely to provoke local conformational changes. Support for this postulate was provided by both the precipitation of inactive oxidized derivatives of glucoamylase $\left(\mathrm{Gl}-7 \mathrm{~W}_{0 x}\right.$ or $-8 \mathrm{~W}_{0 x}$ and $G 2-5 W_{0 x}$ or $-6 W_{0 x}$ ) and the limited proteolysis studies. Oxidized glucoamylase was more susceptible to tryptic digestion as compared with the native enzyme. However, the oxidized and enzymatically inactive forms were much more susceptible than the active derivatives, reflecting structural and/or stability changes to occur with the specific oxidation of the second essential tryptophanyl residue.

Hence, two functionally distinct essential tryptophanyl residues exist in the glucoamylase from A. niger. In the most extensively studied carbohydrase, lysozyme, three essential tryptophanyl residues are described (14). The varying effects elicited by the specific modification of each of these residues indicated their different roles in the mechanism of action $(4,5,7,13$, 26,32 ) and a similar phenomenon may be operative in the glucoamylases. Thus, during the course of NBS oxidation of the A. saitoi glucoamylase (16), there is no linear correlation between loss in activity and loss in ligand binding, in agreement with functionally different behavior for the two essential tryptophanyl residues. By comparison of the rates of NBS oxidation of tryptophanyl residues in both free glucoamylase from R. niveus and its complex with gluconolactone, OHNISHI et al. (21) recently proposed that only one residue is protected. However, earlier results by these workers (19) show that such partially oxidized glucoamylase does bind substrate although it is catalytically inactive. With further oxidation of one tryptophanyl residue, the ability of the $R$. niveus enzyme to bind substrate is also destroyed.

It is not clear why increased reactivity towards NBS was observed when the enzyme was modified in the presence of the substrates, maltose and maltotriose. However, the complexation of the substrates could elicit a transient conformational change with concomitant exposure of the critical tryptophanyl residue $\mathrm{W}_{\mathrm{a}}$. Implicit in this proposal is the assumed inability of the inhibitors to interact with the enzyme to induce a similar conformational response. Starch, on the other hand, provides a temporary protection of $W_{a}$ perhaps simply by hindering access of NBS.

Acarbose served as a useful ligand for preparation of specifically oxidized derivatives of $\mathrm{G} 1$ and G2. Among the investigated glucoamylase inhibitors, this pseudotetrasaccharide had the lowest $K_{i}$ value ( $0.62 \mathrm{nM}$, reference 37$)$. However, a low $K_{i}$ value is not a sufficient requirement for the protection of two residues since another strong, but monomeric inhibitor, deoxynojirimycin (24), protected only one tryptophanyl residue. In spite of its extended chain assumed to accomodate several sub-sites in the binding site region of glucoamylase (10) starch did not effectively prevent oxidation of a second essential tryptophanyl residue. Therefore, the unique protection of two tryptophanyl residues afforded by acarbose could result as a consequence of either conformational changes induced by inhibitor complexation or from direct interaction of the ligand with the critical residue when binding occurs in a different mode. Differences between the acarbose-glucoamylase complex and complexes between the enzyme and other ligands are evident from the UV and fluorescence spectra. The blue shift of the fluorescence emission spectra of glucoamylase complexed with either gluconolactone or maltose indicates a change to a more hydrophobic environment around the affected tryptophanyl residue. The decrease in quantum yield could result from 
conformational changes that alter its intrinsic quenching characteristics $(18,27,36)$. In contrast, acarbose induces a red shift suggesting increased hydrophilicity around the affected tryptophanyl residue(s) and the increased quantum yields imply a decrease of the intrinsic quenching by weakening of the interactions between the affected tryptophanyl residue(s) and other groups of the protein (36). The peak near $300 \mathrm{~nm}$ of the difference spectra of glucoamylase complexed by either gluconolactone or acarbose may be attributed to a tryptophanyl residue influenced by a carboxyl group at the catalytic center $(1,2,8,17)$. The increased intensity of this peak induced by acarbose as compared to that induced by gluconolactone indicates that acarbose perhaps influences more than one tryptophanyl residue. The binding of acarbose to glucoamylase, therefore, appears to involve structural changes that are distinct from those obtained by the other ligands and provides unique protection of two specific tryptophanyl residues.

The only observed difference between the NBS-oxidized derivatives of $\mathrm{G} 1$ and $\mathrm{G} 2$ was in the total number of modified residues. Since G1 is extended by a C-terminal fragment of about 100 amino acid residues $(29,31)$ it is suggested that the two additional susceptible tryptophanyl residues of $\mathrm{Gl}$ are located in this region of the molecule. It cannot be excluded, however, that the presence of this fragment affects the access to tryptophanyl residues in $\mathrm{G} 1$ which are readily modified in G2. Investigations concerning the localisation of the essential residues in the primary structure of Gl and $\mathrm{G} 2$ are currently in progress.

\section{ACKNOWLEDGEMENTS}

We are indebted to professor MARTIN OTTESEN for his encouragement and advice during this work. Dr. MORTEN BJERRUM, Department I, Inorganic Chemistry, University of Copenhagen, is thanked for performing the CD-measurements. The Dichrograph was provided from grant 511-6670 from the Danish "Statens naturvidenskablige Forskningsråd". The Department of Physiology, Carlsberg Laboratory, and the Department of Biotechnology, Carlsberg Re- search Laboratory, are thanked for the use of the Varian 2200 spectrophotometer and the JASCO spectrofluorometer, respectively. The expert technical assistance of Mss. EDITH FLøISTRUP and BODIL CORNELIUSSEN is gratefully acknowledged. Drs. E. TRUSCHEIT and D. D. SCHMIDT, Bayer A. G., are thanked for the generous gift of acarbose and deoxynojirimycin.

\section{REFERENCES}

1. Ananthanarayanan, V. S. \& C. C. Bigelow: Unusual difference spectra of proteins containing tryptophan. I. Studies with model compounds. Biochemistry 8, 3717-3723 (1969)

2. Ananthanarayanan, V. S. \& C. C. Bigelow: Unusual difference spectra of proteins containing tryptophan. II. Studies with proteins. Biochemistry 8, 3723-3728 (1969)

3. Barker. S. A., C. J. Gray \& M. E. Jolley: Photooxidation of glucoamylase I from Aspergillus niger. Biochem. Biophys. Res. Comm. 45, 654-661 (1971)

4. Beddell, C. R., C. C. F. Blake \& S. J. Oatley: An $\mathrm{X}$-ray study of the structure and binding properties of iodine-inactivated Jysozyme. J. Mol. Biol. 97 , 643-654 (1975)

5. Blake, C. C. F., R. Cassels, C. M. Dobson, F. M. Poulsen, R. J.P. Williams \& K.S. Wilson: Structure and binding properties of hen lysozyme modified at tryptophan 62. J. Mol. Biol. 147, 73-95 (1981)

6. Dubois, M.. K. A. Gilles. J. K. Hamilton. P. A. REBERS \& F. SMITH: Colorimetric method for determination of sugars and related substances. Anal. Biochem. 28, 350-356 (1956)

7. Formoso, C. \& L. S. Forster: Tryptophan fluorescence lifetimes in lysozyme. J. Biol. Chem. 250, 3738-3745 (1975)

8. Gray.C.J.\& M. E. Jolley: The role of carboxylic acid groups in the action of glucoamylase I. FEBS lett. 29, 197-200 (1973)

9. Hiromi, K., M. Kawai, N. Suetsugu. Y. Nitta. T. Hosotani, A. Nagao, T. Nakajima \& S. Ono: Kinetic studies on glucoamylase VI. Inhibition of substrate analogues. J. Biochem. 74, 935-943 (1973)

10. Hiromi, K., M. Ohnishi \& A. Tanaka: Subsite structure and ligand binding mechanism of glucoamylase. Mol. Cell. Biochem. 51, 79-95 (1983)

11. Hiromi, K., K. Takahashi. Z. Hamauzu \& S. ONO: Kinetic studies on glucoamylase. J. Biochem. 59, 469-475 (1966) 
12. Hiromi. K. A. TanaKa \& M. OHNishi: Fluorometric studies on the binding of gluconolactone, glucose and glucosides to subsites of glucoamylase. Biochemistry 21, 102-107 (1982)

13. Imoto. T.. L. J. ANDrews. S. K. BANerJee. A. Shrake. L. S. Forster \& J. A. Rupley: Optical properties of lysozyme. J. Biol. Chem. 250, 8275$8282(1975)$

14. Imoto. T.. L. N. Johnson, A. C. T. NorTh, D. C. Phillips \& J. A. Rupley: Vertebrate lysozymes. Enzymes 3rd ed. 7, 665-868 (1972)

15. InOKuChi. N.. M. Inama, T. Takahashi \& M. IRIE: Modification of a glucoamylase from Aspergillus saitoi with 1-cyclohexyl-3(2-morpholinyl(4)-ethyl)carbodiimide. J. Biochem. 91, 125-133 (1982)

16. INOKuChi, N., T. Takahashi, A. Yoshimoto \& M. IRIE: N-Bromosuccinimide oxidation of a glucoamylase from Aspergillus saitoi. J. Biochem. 91, 1661-1668 (1982)

17. Jolley. M. E. \& C. J. Gray: Tryptophanyl and carboxylic acid residues in the active center of glucoamylase I from Aspergillus niger. Carbohyd. Res. 49, 361-370 (1976)

18. Lehrer. S. S. \& G. D. Fasman: The fluorescence of lysozyme and lysozyme substrate complexes. Biochem. Biophys. Res. Comm. 23, 133-138 (1966)

19. OHNISHI. M. \& K. Hiromi: Studies on the subsite structure of amylases IV. Tryptophan residues of glucoamylases from Rhizopus niveus studied by chemical modification with $\mathrm{N}$-bromosuccinimide. J. Biochem. 79, 11-16 (1976)

20. OHNish1. M.. H. KeGAI \& K. Hiromi: Studies on the subsite structure of amylases. I. Interaction of glucoamylases with substrates and analogues studied by difference spectroscopy. J. Biochem. 77, 695-703 (1975)

21. OHNISHI. M.. M. TANIGUChI \& K. Hiromi: Kinetic discrimination of tryptophan residues of glucoamylase from Rhizopus niveus by fast chemical medification with $\mathrm{N}$-bromosuccinimide. Biochim. Biophys. Acta 744, 64-70 (1983)

22. Patchornik. A.. W. B. Lawson. E. Gross \& B WITKOP: The use of N-bromosuccinimide and $\mathrm{N}$-bromoacetamide for the selective cleavage of of C-tryptophanyl peptide bonds in model peptides and glucagon. J. Am. Chem. Soc. 82, 59235927 (1960)

23. SAvel ev. A. N. \& L. M. Firsov: Carboxyl groups in active site of glucoamylase from Aspergillus awamori. Biokhimiya 47, 1618-1620 (1982)

24. SChmidt, D. D. W. Frommer, L. MUller \& E. TruSCHEIT: Glucosidase-Inhibitoren aus Bazillen. Naturwissenschaften 66, 584-585 (1979)
25. Shimahara, $K$ \& T. Takahashi: An infrared spectrophotometric study on the interconversion and hydrolysis of D-glucono- $\gamma$ - and $-\delta$-lactone in deuterium oxide. Biochim. Biophys. Acta 201, 410-415 (1970)

26. Shrake, A. \& J. A. Rupley: Oxindolealanine-62 lysozyme: equilibrium, calorimetric, and kinetic studies of the reaction with $\mathrm{N}$-acetylglucosamine oligosaccharides. Biochemistry 19, 4044-4051 (1980)

27. Shinitzky. M., V.Grisaro, D. M. Chipman \& N SHARON: Influence of inhibitory sugars on the fluorescence of lysozyme. Arch. Biochem. Biophys. 115, 232-233 (1966)

28. SPANDE, T. F. \& B. WITKOP: Determination of the tryptophan content of proteins with $\mathrm{N}$-bromosuccinimide. Meth. Enzymol. XI, 498-506 (1967)

29. Svensson, B., T. G. Pedersen, I. Svendsen, T. SAKAI \& M. OtTESEN: Characterization of two forms of glucoamylase from Aspergillus niger. Carlsberg Res. Commun. 47, 55-69 (1982)

30. SVENSSON, B., K. LARSEN \& I. SVENDSEN: Amino acid sequence of tryptic fragments of glucoamylase G1 from Aspergillus niger. Carlsberg Res. Commun. 48, 517-527 (1983)

31. Svensson, B., K. Larsen, I. Svendsen \& E. Boel: The complete amino acid sequence of the glycoprotein, glucoamylase $\mathrm{G} 1$ from Aspergillus niger. Carlsberg Res. Commun. 48, 529-543 (1983)

32. Tanaka, A., L. S Forster, P. K. Pal \& J. A RuPLEY: The circular dichroism of lysozyme. J. Biol. Chem. 250, 6977-6982 (1975)

33. Tanaka, A., M. Ohnishi \& K. Hiromi: Stoppedflow kinetic studies on the binding of gluconolactone and maltose to glucoamylase. Biochemistry 21, 107-113 (1982)

34. Tanaka, A., M. Ohnishi, K. Hiromi, S. Miyata \& S. MURAO: Static and kinetic studies on the binding of Streptomyces trehalase inhibitor SG1 with Rhizopus glucoamylase. Comparison with glucose and gluconolactone. J. Biochem. 91, 1-9 (1982)

35. Tanaka, A., T. Yamashita. M. Ohnishi \& $\mathrm{K}$. HIROMI: Steady-state and transient kinetic studies on the binding of maltooligosaccharides to glucoamylase. J. Biochem. 93, 1037-1043 (1983)

36. Teale, F. W. J.: The ultraviolet fluorescence of proteins in neutral solution. Biochem. J. 76, 381388 (1960)

37. Truscheit, E., W. Frommer, B. Junge, L. MÚler, D. D. SCHMIDT \& W. WINGENDER: Chemie und Biochemie mikrobieller $\alpha$-GlucosidasenInhibitoren. Angew. Biochem. 93, 738-755 (1981) 